\title{
Calibration Approach for Estimation of Area under Jhum Cultivation in India
}

\author{
Dhirendra Singh ${ }^{1 *}$ and Sandeep Kumar ${ }^{2}$ \\ ${ }^{1}$ Department of Agricultural Statistics, Narendra Deva University of Agriculture \& Technology, \\ Kumarganj, Faizabad-224229 (UP), India \\ ${ }^{2}$ Department of Statistics, Hindu College, University of Delhi-110007, Delhi, India \\ *Corresponding author
}

\section{A B S T R A C T}

\begin{tabular}{|l|}
\hline K e y w o r d s \\
$\begin{array}{l}\text { Stratified multi- } \\
\text { stage random } \\
\text { sampling, Jhum } \\
\text { cultivation, Remote } \\
\text { Sensing, Calibration } \\
\text { estimator. }\end{array}$ \\
\hline Article Info \\
\hline $\begin{array}{l}\text { Accepted: } \\
\text { 21 July 2017 } \\
\text { Available Online: } \\
\text { 10 September } 2017\end{array}$ \\
\hline
\end{tabular}

Jhum or shifting cultivation, which is widespread in the North East India and some parts of Orissa, Jharkhand and Andhra Pradesh, is a primitive practice of cultivation. It involves clearing vegetative/forest cover on land/slopes of hills, drying and burning it before onset of monsoon and cropping on it thereafter. After harvesting is over, the land is left fallow and vegetation regeneration is allowed on it till the plot becomes reusable for the purpose of cultivation in a cycle. When the practice began the jhum cycle was long varying from 20 to 30 years. Thus, it worked well. The cycle is now decreased to $3 / 4$ years. It was estimated that in 1980 about 1326 thousand hectares of area were under jhuming which increased to 1680 thousand hectares in 1990. A stratified multi-stage random sampling design is proposed for selection of sample wherein districts within a state are strata, villages from the first stage of sampling unit and households are the ultimate stage of sampling. The inquiry based approach is used for collection of data. Forest Survey of India uses remote sensing technology for the purpose of estimation of area under jhum cultivation. The assessment is based on digital interpretation of satellite data for the entire country. Besides, individuals have also made attempts to estimate area under jhum in different parts of the country.

\section{Introduction}

Topographic constrain supplement with socio-economic condition of north eastern hilly region of India led the people to take up specific agricultural system which was termed as "Shifting Cultivation" or "Jhum Cultivation". The process of shifting cultivation involves clearing vegetative / forest cover on land / slopes of hills, drying and burning it before onset of monsoon and cropping on it thereafter. After taking one crop the land is left fallow to allow vegetation till it become reusable for cultivation?
The cycle was long varying from 20 to 30 years, but it has now decreased to 2 to 10 years. Jhum cultivation, on the other hand, causes ecological imbalance, induces land degradation problem through soil erosion resulting sedimentation of riverbeds that ultimately causes floods in lower plains. Needs of the people have increased due to link to markets? The spurt in population growth, as high as $4 \%$ in some of the north eastern hill areas has increased the pressure on land. This all led to shortening of fallow 
cycle and reduction in productivity of Jhum cultivation. These areas require immediate attention for better and effective land management system (Borthakur et al., 1976; Kushwaha and Ram Krishna, 1987).

Reliable and accurate information on Jhum land is still lacking in India. The statistics on Jhum land published by various agencies are merely estimate based on subjective methods or generalized information derived on small scale. It was estimated that in 1980 about 1326 thousand hectare area were under Jhuming which increased to 1680 thousand hectare in 1990. In 1984, Central Forestry Commission estimated that about 6.7 million hectare of cultivable area was affected by Jhum in India. As per task force on shifting cultivation, about 70,000 families in Manipur are involved in Jhum cultivation bringing about 90,000 hectare land under system annually. We provided status of Jhum cultivation in North-Eastern Region (NER) (Table 1). Tripathi and Barik (2003) have provided some important aspects on jhum cultivation in NER of India. The table 2 describes the area under jhum cultivation in NER as estimated by different agencies. It is obvious from the table 2 that the area under jhum cultivation is between 2.80 and 7.40 million hectare. This also indicate conflicting estimate of area in 1975 by two agencies viz NE council and FAO.

Forest survey of India (1999) have provided estimate of area under jhum cultivation for different states of NER (Table 3). The ministry of Agriculture has also provided estimates of area under jhum cultivation in different states of NER (Table 4).

The perusal of tables 3 and 4 indicates that the extent of area under jhum cultivation is maximum in Nagaland followed by Mizoram and Manipur. The table also exhibit conflicting estimates of area under jhum cultivation with respect to states of NER provided by two agencies.

However, these statistics are not based on objective and scientific methods. Deb et al., (2001) have made an attempt for mapping of Jhum lands applying Remote Sensing Technique (RST) in Garo Hills of Meghalaya state to restore the ecosystem in the state. No doubt that RTS is an effective technique to map the Jhum land but at the same time ground truthing is required to substantiate the estimates based on RTS. Moreover, RTS can provide estimate of area under current jhuming but it cannot provided reliable estimate of abandon area under jhuming. Therefore, the aim of the present paper is to develop an objective and scientific methodology based on sampling method to obtain estimate of area under Jhum cultivation.

\section{Period of Jhum cultivation and sowing methods}

The dry broadcast or 'punghul' method involves sowing in the month of March/April and harvested in August/ September.

Wet sowing or 'pamphel' is done in the month of May/ June and harvested in October/ November. Transplanted paddy is also sown in the month of May/ June and harvested in October/ November.

\section{Sampling methodology for estimating area under jhum cultivation}

NSSO in its $31^{\text {st }}$ round socio-economic survey (1976-77) had included household schedule on jhum cultivation (Srivastava, 1989). Household approach is considered to be most appropriate for data collection on area under jhum cultivation. Since 1976-77, a lot of improvement in sampling design and estimation methods has been done. 


\section{Sampling design and method of estimation}

We propose stratified two-stage sampling for estimation of area under jhum cultivation. Consider that the state is the population under study. The districts are strata and villages are first stage units (fsu) within district, and household within villages are second stage units (ssu). Let $G$ be the number of districts (strata) in the state. Let $N_{g}$ be the number of villages (fsu) in $g^{\text {th }}$ stratum (district), $g=1,2,3, \ldots \ldots \ldots \ldots$.... Let $N_{g i}$ be the number of households (ssu) in the $i^{\text {th }}$ village $\left(i=1,2,3 \ldots \ldots N_{g}\right)$. We denote the entire population of fsu by $U=\left(U_{1}, U_{2} \ldots \ldots . U_{g} \ldots \ldots . U_{G}\right) \quad$ and the population of in $g^{\text {th }}$ stratum by $U_{g}=\left(U_{1}, U_{2} \ldots \ldots . U_{g_{i}} \ldots \ldots . U_{N_{g}}\right)$.

We further define

$N=\sum_{g=1}^{G} \sum_{i=1}^{N_{g}} N_{g i}$ the total number households in the state

$\bar{N}_{g o}=\frac{1}{N_{g}} \sum_{i=1}^{N_{g}} N_{g i}$, average number of ssu per psu in $g^{\text {th }}$ stratum.

$y_{\text {gik }}=$ The area under jhum cultivation in $k^{\text {th }}$ household of $i^{\text {th }}$ psu in $g^{\text {th }}$ stratum.

$Y_{g i}=\sum_{k=1}^{N_{g i}} y_{g i k}$, total area under jhum cultivation in $i^{\text {th }}$ psu of $g^{\text {th }}$ stratum.

$Y_{g}=\sum_{i=1}^{N_{g}} Y_{g i}$, the total area under jhum cultivation in $g^{\text {th }}$ stratum.
$Y=\sum_{g=1}^{G} Y_{g}$, the total area under jhum cultivation in the state.

\section{Remarks1}

We make the frame of only those households in villages who are practicing jhum cultivation to avoid zero information.

The objective is to estimate $Y=\sum_{g=1}^{G} Y_{g}$, the total area under jhum cultivation in the state. For this purpose, we first estimate $Y_{g}$ by applying suitable sampling design and estimation methods.

Consider that at-first stage, a random sample $s_{g}$ of $n_{g}$ fsu's from $N_{g}$ fsu's in $g^{\text {th }}$ stratum is drawn according to sampling design $P_{g}$ (.) with the inclusion probabilities $\pi_{g i}$ and $\pi_{g i j}$.

At second stage, we draw a random sample $s_{i}$ of size $n_{i}$ from $N_{g i}$ elements from the selected $i^{\text {th }}$ fsu in $g^{\text {th }}$ stratum $\left(i=1,2,3 \ldots \ldots \ldots n_{g}\right)$ according to design $P_{i}(\cdot)$ with inclusion probabilities $\pi_{g k / i}$ and $\pi_{g k / i} \cdot$ We also define

$\Delta_{g i j}=\pi_{g i j}-\pi_{g i} \pi_{g j} \quad$ with $\quad \tilde{\Delta}_{g i j}=\Delta_{g i j} / \pi_{g i j} ;$ $\Delta_{g H}=\pi_{g H}-\pi_{g k} / i \pi_{g l}$, with $\tilde{\Delta}_{g H}=\frac{\Delta_{g k} / i}{\pi_{g k}}$

The Horvitz-Thompson estimator of $Y_{g}$ is constructed as

$\hat{Y}_{g(H T)}=\sum_{s_{s}} \hat{Y}_{g i(H T)} / \pi_{g i}=\hat{Y}_{g(H T)}=\sum_{s_{s}} \sum_{s_{i}} y_{g i k} / \pi_{g i} \pi_{g k} / i$ 
The variance of $\hat{Y}_{g}$ is given by

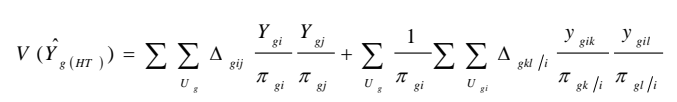

The unbiased estimator of $V\left(\hat{Y}_{g}\right)$ is given by

$$
\begin{aligned}
& \hat{V}\left(\hat{Y}_{g(H T)}\right)=\sum \sum_{s_{g}} \tilde{\Delta}_{g i j} \frac{\hat{Y}_{g i(H T)}}{\pi_{g i}} \frac{\hat{Y}_{g j(H T)}}{\pi_{g j}}+\sum_{s_{g}} \frac{\hat{V}_{i}}{\pi_{g i}}, \quad \text { where } \\
& \hat{V}_{i}=\sum \sum_{s_{i}} \tilde{\Delta}_{g k l / i} \frac{y_{g i k}}{\pi_{g k / i}} \frac{y_{g i l}}{\pi_{g l / i}}(3.3)
\end{aligned}
$$

Now, the estimator of $Y$, its variance and variance estimator are given by

$\hat{Y}=\sum_{g=1}^{G} \hat{Y}_{g(H T)}, \quad V(\hat{Y})=\sum_{g=1}^{G} V\left(\hat{Y}_{g(H T)}\right) \quad$ and $\hat{V}(\hat{Y})=\sum_{g=1}^{G} \hat{V}\left(\hat{Y}_{g(H T)}\right)$

If sampling design is simple random sampling without replacement (SRSWOR) at both the stages, say, SI, then $\hat{Y}_{g(H T)}$ reduces as

$$
\begin{aligned}
& \hat{Y}_{g(S I)}=\frac{N_{g}}{n_{g}} \sum_{s_{g}} N_{g i} \bar{y}_{g i}=\frac{N_{g}}{n_{g}} \sum_{s_{g}} \hat{Y}_{g i}, \\
& \bar{y}_{g i}=\frac{1}{n_{i}} \sum_{i=1}^{n_{i}} y_{g i k} \text { (3.5) }
\end{aligned}
$$

The variance of $\hat{Y}_{g(S I)}$ is given by

$$
V\left(\hat{Y}_{g(S I)}\right)=N_{g}^{2} \frac{\left(1-f_{g}\right)}{n_{g}} S_{b y g}^{2}+\frac{N_{g}}{n_{g}} \sum_{U_{g}} N_{g i}^{2} \frac{\left(1-f_{i}\right)}{n_{i}} S_{y g i}^{2}
$$

$$
\text { Where, } \quad f_{g}=\frac{n_{g}}{N_{g}}, \quad f_{i}=\frac{n_{i}}{N_{g i}} \text {; }
$$

$$
\begin{array}{ll}
S_{b y g}^{2}=\frac{1}{N_{g}-1} \sum_{U_{g}}\left(Y_{g i}-\tilde{Y}_{g}\right)^{2} & \text { with } \\
\tilde{Y}_{g}=\frac{1}{N_{g}} \sum_{U_{g}} Y_{g i} & \text { an } \\
S_{y g i}^{2}=\frac{1}{N_{g i}-1} \sum_{U_{g i}}\left(Y_{g i k}-\bar{Y}_{g i}\right)^{2} \text { with } \bar{Y}_{g i}=\frac{Y_{g i}}{N_{g i}} .
\end{array}
$$

The unbiased variance estimator is given by

$$
\hat{V}\left(\hat{Y}_{g(S I)}\right)=N_{g}^{2} \frac{\left(1-f_{g}\right)}{n_{g}} s_{b y g}^{2}+\frac{N_{g}}{n_{g}} \sum_{s_{g}} N_{g i}^{2} \frac{\left(1-f_{i}\right)}{n_{i}} s_{y g i}^{2}
$$

Where

$$
s_{b y g}^{2}=\frac{1}{n_{g}-1} \sum_{s_{g}}\left\lceil N_{g i} \bar{y}_{g i}-\left(\frac{1}{n_{g}} \sum_{s_{g}} N_{g i} \bar{y}_{g i}\right)\right]^{2}
$$

and $s_{y g i}^{2}=\frac{1}{n_{i}-1} \sum_{s_{i}}\left(y_{g i k}-\bar{y}_{g i}\right)^{2}$.

Now, the estimator of $Y$, its variance and variance estimator are given by

$$
\begin{aligned}
& \hat{Y}_{(S I)}=\sum_{g=1}^{G} \hat{Y}_{g(S I)}, \quad V\left(\hat{Y}_{(S I)}\right)=\sum_{g=1}^{G} V\left(\hat{Y}_{g(S I)}\right) \quad \text { and } \\
& \hat{V}\left(\hat{Y}_{(S I)}\right)=\sum_{g=1}^{G} \hat{V}\left(\hat{Y}_{g(S I)}\right)(3.8)
\end{aligned}
$$

\section{Use of auxiliary information to improve the estimates of area under jhum cultivation}

There could be various information related to area under jhum land which can be used as auxiliary information to get more precise estimate. For example, land holding size of the households, family size etc.

If the auxiliary information is available at fsu level, then calibration approach of Deville and Särndal (1992) can be used improve the estimate of area. 
Table.1 Shifting cultivation in the N.E. Region

\begin{tabular}{|l|c|c|c|c|}
\hline State & $\begin{array}{c}\text { Annual Area } \\
\text { under shifting } \\
\text { cultivation } \\
\text { (sq. Kms) }\end{array}$ & $\begin{array}{c}\text { Fallow period } \\
\text { (in years) }\end{array}$ & $\begin{array}{c}\text { Min. Area under } \\
\text { shifting cultivation } \\
\text { one time or other } \\
\text { (sq.kms) }\end{array}$ & $\begin{array}{c}\text { No. of families } \\
\text { practicing } \\
\text { shifting } \\
\text { cultivation }\end{array}$ \\
\hline Arunachal Pradesh & 700 & $3-10$ & 2100 & 54000 \\
\hline Assam & 695 & $2-10$ & 1392 & 58000 \\
\hline Manipur & 900 & $4-7$ & 3600 & 70000 \\
\hline Meghalaya & 530 & $5-7$ & 2650 & 52290 \\
\hline Mizoram & 630 & $3-4$ & 1890 & 50000 \\
\hline Nagaland & 190 & $5-8$ & 1913 & 116046 \\
\hline Tripura & 223 & $5-9$ & 1115 & 43000 \\
\hline Total & 3869 & & 14660 & 443336 \\
\hline
\end{tabular}

Table.2 Area under shifting cultivation in north-east India as estimated by different agencies

\begin{tabular}{|l|c|c|}
\hline \multicolumn{1}{|c|}{ Agency } & year & Area(million ha) \\
\hline North-Eastern council & 1975 & 2.80 \\
\hline FAO & 1975 & 7.40 \\
\hline Task Force on Shifting cultivation, Ministry of Agriculture & 1983 & 3.81 \\
\hline Forest Survey of India & 1999 & 1.73 \\
\hline
\end{tabular}

Table.3 Area affected by shifting cultivation in different north-eastern states as per the estimate of Forest survey of India (1999)

\begin{tabular}{|l|l|l|l|l|l|l|l|l|}
\hline State & $\begin{array}{l}\text { Arunachal } \\
\text { Pradesh }\end{array}$ & Assam & Manipur & Meghalaya & Mizoram & Nagaland & Tripura & Total \\
\hline $\begin{array}{l}\text { Cumulative area } \\
\text { (mil ha) shifting } \\
\text { cultivation(1987 } \\
\text { to 1997) }\end{array}$ & 0.23 & 0.13 & 0.36 & 0.18 & 0.38 & 0.39 & 0.06 & 1.73 \\
\hline
\end{tabular}

Table.4 Area under shifting cultivation in north-east India as per Ministry of Agriculture

\begin{tabular}{|l|l|l|l|l|l|l|l|l|}
\hline State & $\begin{array}{l}\text { Arunacha } \\
\text { 1 Pradesh }\end{array}$ & Assam & $\begin{array}{l}\text { Manipu } \\
\mathrm{r}\end{array}$ & $\begin{array}{l}\text { Meghalay } \\
\mathrm{a}\end{array}$ & $\begin{array}{l}\text { Mizora } \\
\mathrm{m}\end{array}$ & $\begin{array}{l}\text { Nagalan } \\
\mathrm{d}\end{array}$ & $\begin{array}{l}\text { Tripur } \\
\mathrm{a}\end{array}$ & $\begin{array}{l}\text { Tota } \\
1\end{array}$ \\
\hline $\begin{array}{l}\text { Area(million } \\
\text { ha) under } \\
\text { shifting } \\
\text { cultivation }\end{array}$ & 0.26 & 0.31 & 0.36 & 0.26 & 0.04 & 0.63 & 0.10 & 1.96 \\
\hline $\begin{array}{l}\text { No. } \\
\text { families } \\
\text { practicing } \\
\text { shifting } \\
\text { cultivation }\end{array}$ & 54,000 & 58,000 & 70,000 & 52,290 & 50,000 & $1,16,046$ & 43,000 & $\begin{array}{l}4,43, \\
336\end{array}$ \\
\hline
\end{tabular}


Recently, Kaustav et al., (2016) have developed calibration based regression type estimator of the population total under twostage sampling design when the auxiliary information is available at fsu level.

This can be extended straight way to stratified two-stage sampling design. Let $X_{g i}$ be the total of an auxiliary variable $x$ at $i^{\text {th }}$ fsu level in $g^{\text {th }}$ stratum, which is assumed to be known.

Then $X=\sum_{g=1}^{G} \sum_{i=1}^{N_{g}} X_{g i}$ is also known. The Horvitz -Thompson estimator given in (3.1) can be written as

$$
\hat{Y}_{g(H T)}=\sum_{s g} a_{g i} \hat{Y}_{g i(H T)}, a_{g i}=\frac{1}{\pi_{g i}}
$$

The design weight $a_{g i}$ can be calibrated using known auxiliary information at fsu level. Let $w_{g i}$ be the calibrated weight. Then, we have calibration estimator of $Y_{g}$ as

$$
\hat{Y}_{g c}=\sum_{s g} w_{g i} \hat{Y}_{g i(H T)}
$$

$w_{g i}$ is obtained by minimizing chi-square type distance measure $\sum\left(w_{g i}-a_{g i}\right)^{2} / a_{g i} q_{g i}$ subject to the constraints

$$
\sum_{s g} w_{g i} X_{g i}=\sum_{i=1}^{N_{g}} X_{g i}=X_{g} \text { and } \sum_{s g} w_{g i}=\sum_{s g} a_{g i}
$$

Finally, the estimator $\hat{Y}_{g c}$ takes the form

$$
\hat{Y}_{g c}=\hat{Y}_{g(H T)}+\hat{B}\left(X_{g}-\sum_{s g} a_{g i} X_{g i}\right), \quad \text { where }
$$

$$
\hat{B}=\frac{\sum_{s g} a_{g i} \hat{Y}_{g i(H T}\left(X_{g i}-\frac{\sum_{s g} a_{g i} X_{g i}}{\sum_{s g} a_{g i}}\right)}{\sum_{s g} a_{g i} X_{g i}^{2}-\left(\sum_{s g} a_{g i} X_{g i}\right)^{2} / \sum_{s g} a_{g i}}
$$

Under SRSWOR, the (4.4) reduces to

$$
\hat{Y}_{g c(S I)}=\frac{N_{g}}{n_{g}} \sum_{s_{s i}} \hat{Y}_{g i}+\frac{\sum_{s g} \hat{Y}_{g i}\left(X_{g i}-\sum_{s_{g}} X_{g i} / n_{g}\right)}{\sum_{s_{s}} X_{g i}^{2}-\left(\sum_{s_{s}} X_{g i}\right)^{2} / n_{g}}\left[X_{g}-\frac{N_{g}}{n_{g}} \sum_{s g} X_{g i}\right]
$$

Approximate variance and variance estimator of $\hat{Y}_{g c}$ are given by

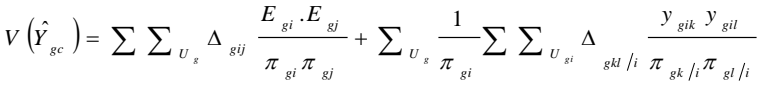

and

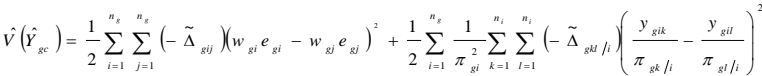

Where $E_{g i}=Y_{g i}-\beta X_{g i}, e_{g i}=\hat{Y}_{g i}-\hat{B} X_{g i}$ and $\beta=\frac{\sum_{U_{g}} Y_{g i} X_{g i}-\frac{1}{N_{g}}\left(\sum_{U_{g}} Y_{g i}\right)\left(\sum_{U_{g}} X_{g i}\right)}{\sum_{U_{g}} X_{g i}^{2}-\left(\sum_{U_{g}} X_{g i}\right)^{2} / N_{g}}$

To find out the calibration estimator of $Y$, we can sum up $\hat{Y}_{g c}$ over G strata, i.e $\hat{Y}_{c}=\sum_{g=1}^{G} \hat{Y}_{g c}$

The variance and variance estimator can be obtained easily as done in section-3.

An attempt has been made to high light the advantages of jhum cultivation. Present status of estimates of area under jhum land reported 
by various agencies has been presented and discussed. Some appropriate sampling methodologies have been developed for estimation of area under jhum land. These methodologies can be applied to obtain more precise estimates of area along with level of standard errors.

\section{References}

Borthakur, D.N., Awasthi, R.P. and Ghosh, S.P. 1976. Alternative system of farming for increasing Productivity in jhum land. In shifting cultivation in North-East India. pp. 63-76.

Deb, T.K., Shaho, N.C., Saini, K.M. and Das, S.N. 2001. Mapping of jhum land using Remote Sensing Technique for restoration of Ecosystem- A case study of Garo Hills, Meghalaya state. Jour. Agril. Physics, Vol.1, No.1, 25-27.

Deville, J.C., and Särndal, C.E. 1992. Calibration estimators in survey sampling. J. Amer. Statist. Assoc., 87, 376-382.

Kaustav, A., Sud, U.C., Hukum Chandra and
Biswas 2016. Calibration based regression type estimator of the population total under two stage sampling design. J. Indian Society Agril. Statistics.Vol.70 (1); 19-24.

Kushwaha, S.P.S., and Ram Krishna, P.S. 1987. An analysis of some agoecosystem types of North-Eastern India. Proc. Indian National Science Academy, B53 (2); 53-57.

Srivastva, A.K., 1989 Agriculture statistics system in Hill area of North-East India. Proc. of symposium on "Use of agricultural and environmental statistics for development of Hill and mountain region" J. Indian Society of Agril. Statistics, pp. 56-60, New Delhi.

Tripathi, R.S., and Barik, S.K. 2003. Shifting cultivation in North-East India. Proc. of Approaches for increasing agricultural productivity in hill and mountain ecosystem. Eds: B.P. Bhah, K.M., Bujarbaruvah, Y.P. Sharma and Patiram, pp. 317-322, ICAR Research complex for New region, union, Meghalaya.

\section{How to cite this article:}

Dhirendra Singh and Sandeep Kumar. 2017. Calibration Approach for Estimation of Area under Jhum Cultivation in India. Int.J.Curr.Microbiol.App.Sci. 6(9): 1725-1731. doi: https://doi.org/10.20546/ijcmas.2017.609.213 